MORPHOLOGICALSTUDY ON TORUS PALATINUS IN ADULT HUMAN SKULLS

\title{
T.L.Anbumani ${ }^{1}$, M.Raja ${ }^{* 2}$, R.Sridharan ${ }^{3}$, A.Thamarai Selvi ${ }^{4}$.
}

${ }^{1}$ Professor and Head, Department of Anatomy. Karpaga Vinayaga Institute of Medical Sciences, Madurantakam Taluk, Kanchipuram District, Tamil Nadu, India.

*2 Postgraduate, Karpaga Vinayaga Institute of Medical Sciences, Madurantakam Taluk, Kanchipuram District,Tamil Nadu, India.

${ }^{3}$ Postgraduate, Karpaga Vinayaga Institute of Medical Sciences, Madurantakam Taluk, Kanchipuram District,Tamil Nadu, India.

${ }^{4}$ Assistant Professor, Karpaga Vinayaga Institute of Medical Sciences, MadurantakamTaluk, Kanchipuram District,Tamil Nadu, India.

\section{ABSTRACT}

Background: The torus palatinus or palatinus tori, is a type of bony growth or protrusion at the roof of the mouth, or bony hard palate. More specifically, it appears at the mid-line of this part of the mouth. Although it is not a life-threatening condition, more serious cases might require medical attention. Usually, this growth has a diameter of about $2 \mathrm{~cm}$, although it can be bigger since it tends to grow, albeit slowly. Although palatial tori are generally not painful, bigger ones have a possibility of presenting irritation. Also, if injured, the protrusion could become painful with the development of ulcers, as well as be slow to heal due to lack of an efficient number of blood vessels. This condition can cause difficulty in eating and drinking, which is a major symptom of the problem. The appearance of tori palatinus can also interfere with the placement of dentures, and infection could spread to the bone or palate itself. In such cases, which also include pain and ulceration, the patient would need to see a medical professional.

Materials and Methods: The hard bony palate was observed for any abnormality in 50 Adult dry human skulls in the Department of Anatomy, KarpagaVinayaga Institute of Medical Sciences, Chinnakolambakkam, Madurantakam taluk, Tamilnadu.

Results and Conclusion: There was a bony protrusion from hard palate with irregular shape and variable size in 6 skulls (12\%). Based on this observation, literatures have been searched and it was found to be Torus palatine. Therefore, a thorough knowledge of complex anatomy and embryology of hard palate is of utmost importance to neurosurgeons and dental surgeons, maxillofacial surgeons, and prosthodontics people.

KEY WORDS: Skull, Torus Palatinus, Palate.

Address for Correspondence: Dr.M.Raja,M.D (Anatomy), Postgraduate, Karpaga Vinayaga Institute of Medical Sciences, Madurantakam Taluk, Kanchipuram District,Tamil Nadu, India.

E-Mail: Jeyamraja2015@gmail.com

Access this Article online Journal Information

Quick Response code International Journal of Anatomy and Research

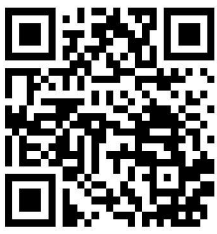

DOI: $10.16965 /$ ijar.2019.178

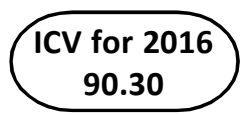
ISSN (E) 2321-4287 | ISSN (P) 2321-8967 https://www.ijmhr.org/ijar.htm DOI-Prefix: https://dx.doi.org/10.16965/ijar

\section{Article Information}

Received: 17 Mar 2019

Peer Review: 18 Mar 2019

Revised: None
Accepted: 16 Apr 2019

Published (O): 05 May 2019

Published (P): 05 May 2019

\section{INTRODUCTION}

Torus palatines are bony exostosis found on the palate consisting of mature cortical bone and trabecular bone [1]. The torus palatinus, or 
palatinus torus, is a type of bony growth or protrusion at the roof of the mouth, or palate. More specifically, it appears at the mid-line of hard palate [2]. Although it is far from a life-threatening condition, more serious cases might require medical attention. It is called tori palatinus, or palatal tori, in plural form.

Usually, this growth has a diameter of about 2 $\mathrm{cm}$, although it can be bigger since it tends to grow, albeit slowly. It feels smooth and can be knob-shaped or broad and flat, and it can vary in size, from a tiny nodule or spindle to a massive bump. In some instances, tori palatinus combine to form a growth similar to a tumor, but in other cases, it occurs as a singular growth.

Medical research has shown that the growths are more common in females than in males [2]. They are also more common in Native Americans, Asians, and Inuit Eskimos than in any other racial or ethnic group. In the United States, it occurs in about $1 / 4$ to $1 / 3$ of the population. The condition usually appears during the early years of adulthood i.e in second and third decades of life. There is a possibility of growing in size as age advances. The growth, however, shrinks as one grows older, due to the reabsorption of the bones.

The cause of torus palatinus is yet to be determined, but some researchers believe that it could be the result of genetics. Although palatial tori are asymptomatic generally not painful, bigger ones have a possibility of presenting irritation. Also, if injured, the protrusion could become painful with the development of ulcers, as well as be slow to heal due to lack of an efficient number of blood vessels. This condition can cause difficulty in eating and drinking, which is a major symptom of the problem.

The appearance of tori palatinus can also interfere with the placement of dentures, and infection could spread to the bone or palate itself. In such cases, which also include pain and ulceration, the patient would need to see a medical professional. Surgery is the standard treatment, and it usually involves removal of a certain amount of bone in the palate. Prognosis for patients after surgery is generally excellent, with no known major complications.

Aims and Objectives: The study is aimed, to study and provide the knowledge about any presence of any abnormality or variations on the surface of hard palate.

\section{MATERIALS AND METHODS}

During routine undergraduate demonstration, the hard bony palate was observed for any abnormality in 50 Adult dry human skulls in the Department of Anatomy, KarpagaVinayaga Institute of Medical Sciences, Chinnakolambakkam, Madurantakam taluk, Tamilnadu.

Inclusion Criteria: Adult Healthy Human skulls were taken for study.

Exclusion Criteria: Deformed, Broken and Eroded skulls.

\section{OBSERVATIONS}

Fig.1: Shows an irregular bony outgrowth on the surface of hard palate (Torus Palati)

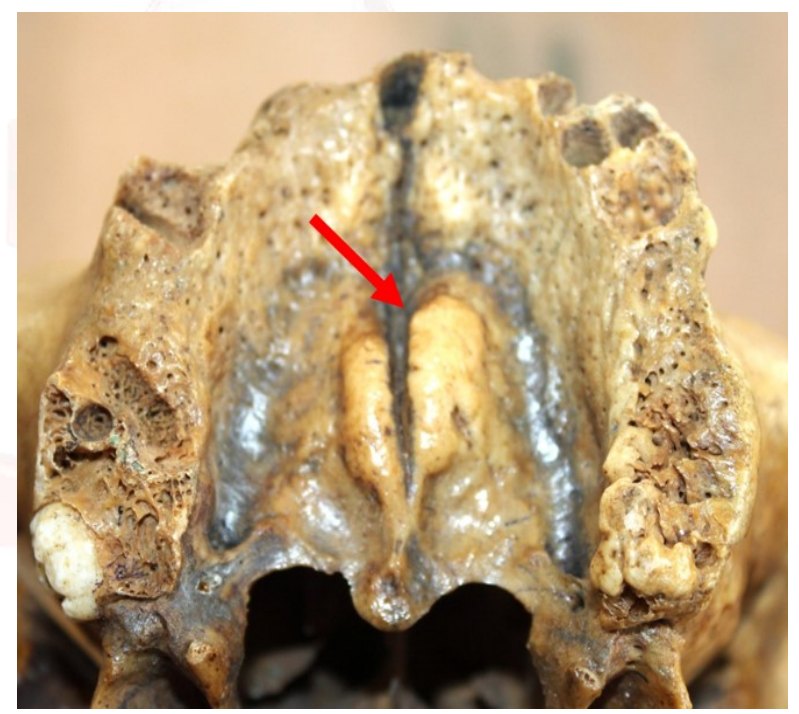

Table 1: Show the percentage of Torus Palati.

\begin{tabular}{|c|c|c|}
\hline $\mathrm{N}=50$ & $\begin{array}{c}\text { Number of } \\
\text { hard palate } \\
\text { with normal } \\
\text { features }\end{array}$ & $\begin{array}{c}\text { Number of hard } \\
\text { palate with bony } \\
\text { outgrowth (Torus } \\
\text { Palati) }\end{array}$ \\
\hline $\begin{array}{c}\text { Total number of studied } \\
\text { skulls:50 nos. }\end{array}$ & 44 & 6 \\
\hline Percentage (\%). & $88 \%$ & $12 \%$ \\
\hline
\end{tabular}

During routine undergraduate demonstration, the hard bony palate was observed for any abnormality in the base of 50 Adult dry human skulls. There was a bony protrusion from hard palate with irregular shape and variable size in 6 skulls (12\%). This is depicted in Table.1.Based on this observation, literatures have been searched and it was found to be Torus palatine. 
These Torus palatines was studied for a review of its morphology, and were compared with previous studies. Figure.1 shows an irregular bony outgrowth on the surface of hard palate ( torus palati)

\section{DISCUSSION}

The tori (meaning "to stand out" or "lump" in Latin) are exostosis that are formed by a dense cortical and limited amount of bone marrow, and they are covered with a thin and poorly vascularized mucosa. They are usually located at the longitudinal ridge of the half palatine, on the union of the palatine apophysis of the maxillae ${ }^{2}$.Most of the Research workers have did their study on their Out Patients Dental Clinics. Their datas are compared with the present study in bar chart 1 . The present study is based on the mere macroscopic observation of palate surface in the base of the skull.

Table 2: Incidences of Torus Palatini in Dry adult Human Skulls. (Comparing Present study with other Research Workers).

\begin{tabular}{|c|c|c|c|c|}
\hline Research Workers & $\begin{array}{c}\text { Santosh Patil et al } \\
{[3] \text { (2014) }}\end{array}$ & $\begin{array}{c}\text { Al Quran FA et al [4] } \\
\text { (2006) }\end{array}$ & $\begin{array}{c}\text { AsishKumar et al [5] } \\
\text { (2017) }\end{array}$ & $\begin{array}{c}\text { Present } \\
\text { Study }\end{array}$ \\
\hline Population & Indians & Jordan & Malaysia & India \\
\hline Percentage & $1.30 \%$ & $29.80 \%$ & $43 \%$ & $12 \%$ \\
\hline
\end{tabular}

\author{
Bar Chart: Percentage \\ comparison of Torus Palatini.
}

\section{CONCLUSION}

The cause of torus palatinus is yet to be determined, but some researchers believe that it could be the result of genetics. The variations reported in present study and in other studies may be due to various factors such as race, constitution and genetics and geographical factors. The increasing use of modern diagnostic procedures and new surgical approaches has created a need for much more detailed anatomical studies and explanations. Their presence needs changes in denture design during fabrication of prosthesis which has to be remembered by dentist. Therefore, a thorough knowledge of anatomy and complex embryology of hard palate is of utmost importance to neurosurgeons and dental surgeons, maxillofacial surgeons, and prosthodontics people.

\section{Conflicts of Interests: None}

\section{REFERENCES}

[1]. Regezi JA,Sciubba JJ-Oral pathology:Clinical Pathological correlations, W.B.Saunders. Co.Philadelphia, 1989;386-387.

[2]. Garcia etal, Current status of T orus Mandibularis and Torus Palatinus, . Med Oral Patol Oral Cir Bucal. 2010 Mar 1;15(2):e353-60.

[3]. Patil S, Maheshwari S, Khandelwal SK. Prevalence of toruspalatinus and torus mandibularis in an Indian population.Saudi J Oral Sci, 2014;1(2):94-97.

[4]. Al Quran FA, Al-Dwairi ZN. Torus palatinus and torusmandibularis in edentulous patients. J Contemp Dent Pract,2006;7(2):112-119.

[5]. Ashish Kumar Singh, Srinivas Sulugodu Ramachandra, Shelly Arora, Daniel Devaprakash Dicksit, C.G. Kalyan, and Priyanshi Singh Prevalence of oral tori and exostosis in Malaysian population - A cross-sectional study. J Oral Biol Craniofac Res. 2017 Sep-Dec;7(3):158-160. 
T.L.Anbumani, M.Raja, R.Sridharan, A.Thamarai Selvi. MORPHOLOGICAL STUDY ON TORUS PALATINUS IN ADULT HUMAN SKULLS.

[6]. Jainkittivong A, Apinhasmit W, Swasdison S. Prevalence and clinical characteristics of oral tori in 1,520 Chulalongkorn University Dental School patients. Surg Radiol Anat, 2007;29(2):125-131.

[7]. Bayaty etal:An epidemiological study of tori among 667 dental outpatients in Trinilaed \&Tobago West Indies, Int Dent.J.2001;51:300-4.
[8]. Matthews GP. Mandibular and palatine tori and their etiology.J Dent Res, 1933;13(2):245.

[9]. Sellevold BJ. Mandibular torus morphology. Am J Phys Anthropol, 1980;53(4):569-572.

[10]. Chew CL, Tan PH. Torus palatinus. A clinical study. AustDent J, 1984;29(4):245-248.

How to cite this article:

T.L.Anbumani, M.Raja, R.Sridharan, A.Thamarai Selvi. MORPHOLOGICAL STUDY ON TORUS PALATINUS IN ADULT HUMAN SKULLS. Int J Anat Res 2019;7(2.2):6597-6600. DOI: 10.16965/ijar.2019.178 